\title{
Managing strategic system-building networks in emerging business fields: A case study of the Dutch smart grid sector
}

\author{
Julia Planko*, Maryse M.H. Chappin, Jacqueline M. Cramer, Marko P. Hekkert \\ Utrecht University, Copernicus Institute of Sustainable Development, Heidelberglaan 8, 3584 CS Utrecht, The Netherlands
}

\section{A R T I C L E I N F O}

\section{Keywords:}

Network management

Strategic business nets

Collective system building

Smart grids

Eco-innovations

\begin{abstract}
A B S T R A C T
Companies that wish to launch innovative sustainability technologies can collaborate in strategic networks of actors from industry, government and research institutes to pro-actively build a business ecosystem around their new technology. This is called collective system building. In this paper, we examine how to effectively manage networks for collective system building. Based on a review of the literature, we identify the key factors of effective network management and we propose a conceptual framework for network management at the network level. Subsequently, we conduct a multiple-case study in the Dutch smart grid sector to examine how these key factors are implemented by system-building networks. We find differences with the existing network management literature regarding network composition, network management structure, governance modes, decisionmaking processes, project management, the free-rider problem and trust-building mechanisms. Our study contributes to a better understanding of effective management of system-building networks, which in turn can lead to greater success in establishing new business fields. We contribute to the literature on strategic business networks, specifically on emerging business networks building new business fields.
\end{abstract}

\section{Introduction}

Corporate collaboration in inter-organizational networks has become a predominant form of business management (Gulati, 1998; Hagedoorn \& Schakenraad， 1994; Möller \& Svahn， 2003， 2009; Nalebuff \& Brandenburger, 1996). A critical success factor for businesses will be the ability to build and develop strategic networks (Partanen \& Möller, 2012), especially in fast-changing technology-intensive sectors, in which the products and services offered are not only complex in themselves, but also include a large variety of complementary products and services (Partanen \& Möller, 2012). Due to high velocity markets, the high level of technological complexity and the diversity of resources and capabilities required to develop the necessary infrastructure, it is almost impossible for a single firm to create new technology (Möller \& Svahn, 2009). Such radical innovation often requires building a new business field (Möller, 2010; Möller \& Svahn, 2009). The creation and commercialization of new business fields is carried out by linked actors in complex inter-organizational networks (Möller \& Svahn, 2009), whose aim is to create state-of-the-art products and services and high efficiency production and business processes, which generate added value for customers (Möller, 2010). In other words, a supportive ecosystem is necessary for radical innovation.

The creation of a supportive ecosystem around a new innovation is one of the crucial success factors for commercializing radical innovations (Aarikka-Stenroos \& Lehtimäki, 2014). In fact, the main external barrier to radical innovation is an undeveloped network and ecosystem around the innovation (Sandberg \& Aarikka-Stenroos, 2014). Therefore, to increase market success, firms intentionally build network relations and develop new business fields in innovation networks (AarikkaStenroos, Sandberg, \& Lehtimäki, 2014). The development of such an ecosystem is largely beyond a single firm's influence and needs to take place in networks (Sandberg \& Aarikka-Stenroos, 2014).

Building a supportive business ecosystem is relevant for any firm aiming to develop and commercialize radical innovation, but especially for radical sustainability innovations. Sustainability transitions cause actors to operate in great uncertainty and require transformative change (Knight, Pfeiffer, \& Scott, 2015). Society-wide changes are necessary for the successful commercialization of innovative sustainability technologies (Geels, 2002, 2005; Kemp, Schot, \& Hoogma, 1998). To realize such changes, firms need to collaborate with other actors (Musiolik, Markard, \& Hekkert, 2012), as together they can proactively change their environment and build a favorable ecosystem in which their innovative technology can flourish. In transition literature, this process is called 'collective system building'. Collective system building is defined as the "processes and activities that firms can conduct in networks to collectively create a favorable environment for their

\footnotetext{
* Corresponding author

E-mail addresses: julia.planko@hu.nl (J. Planko), M.M.H.Chappin@uu.nl (M.M.H. Chappin), J.M.Cramer@uu.nl (J.M. Cramer), M.P.Hekkert@uu.nl (M.P. Hekkert).
} 
innovative sustainability technology" (Planko, Cramer, Chappin, \& Hekkert, 2016, p. 2329). It aims at developing and optimizing technology, triggering socio-cultural changes, and creating a market for the new technology, including changes in governmental regulations and user behavior.

System-building networks can be classified as strategic networks, i.e. networks created intentionally by three or more organizations with the aim of achieving a common goal, and with deliberately created structures and negotiated roles and responsibilities (Järvensivu \& Möller, 2009; Möller \& Rajala, 2007). These strategic networks need to be managed intensively in order to be effective (Provan, Fish, \& Sydow, 2007; Rampersad, Quester, \& Troshani, 2010; Turrini, Cristofoli, Frosini, \& Nasi, 2010). Moreover, different types of strategic networks need to be managed differently (Järvensivu \& Möller, 2009): networks in established industries or aiming at incremental change need different management and coordination mechanisms than networks operating in emerging business fields, so-called 'emerging business nets' (Möller \& Rajala, 2007). System-building networks are emerging business nets, as they operate in great uncertainty in emerging business fields, trigger radical systemwide changes, and combine old and new actors. The majority of network management research has focused on networks in more established business fields (Choi \& Hong, 2002; Håkansson \& Persson, 2004; Wilhelm, 2011), and the management of networks in emerging business nets is under-researched (Möller \& Svahn, 2009). The few studies on network management in emerging business fields focus on the firm's perspective, examining how managers can reap the most benefits for their firm from their network collaboration (e.g. Ford \& Håkansson, 2013; Freytag \& Ritter, 2005; Ritter, Wilkinson, \& Johnston, 2004). However, rather than management within networks to reap firm-level benefits, this paper focuses on the management of networks to reap system-level benefits.

In sum, network management at the network level in emerging business fields is under-explored (Aarikka-Stenroos et al., 2014), and more empirical research is required to generalize exploratory findings (Heidenreich, Landsperger, \& Spieth, 2016; Rampersad et al., 2010). Therefore, it is important to investigate the key drivers of effective network management at the network level (Rampersad et al., 2010). The aim of our paper is to gain a better understanding of how systembuilding networks are managed to build a new business ecosystem. Our research question is "how are networks for collective system building managed to reach their collective system-building objectives?" From the literature, we have identified the key factors of network management to achieve common objectives, and we empirically examined whether these key factors were relevant for system-building networks in the Dutch smart grid sector and how they are manifested in these networks.

This paper contributes to the emerging theory of network management (e.g. Järvensivu \& Möller, 2009; Möller, 2010; Möller \& Halinen, 1999; Ritter \& Gemünden, 2003a). Instead of focusing on the firm, we study network management and the outcomes at the network level, in the context of building a new business field or business ecosystem for sustainability technologies. We provide additional insights into key factors of network management in emerging business fields.

\section{Setting the scene: sustainability transitions, the smart grid sector and system-building networks}

To investigate how collaborative inter-organizational networks are managed to build new business fields, we chose the empirical case of the Dutch smart grid sector, a field in which actors develop interdependent and compatible products and services under great uncertainty, and collaborate to establish a new business field.

The Dutch smart grid sector is an emerging technological system. A smart grid is an electricity network combined with an ICT network, adapted to renewable energy sources. Its 'smartness' allows balancing the supply and demand of energy on the grid, thus making the electricity grid more sustainable, efficient and robust (Verbong, Beemsterboer, \& Sengers, 2013). For example, smart washing machines enable users to do their laundry at the very moment when there is a surplus of energy on the grid, caused by other users' solar panels producing excess energy because of sunny conditions. Essentially, smart grids are not one technology, but a complex set of intertwined technologies.

Transition to a new technological regime is a long and difficult process. In order to implement their products and to achieve a sustainability transition, innovative actors build coalitions not only to develop new technologies, but also to create markets, build infrastructures and achieve changes in user practices, regulations, policy and cultural meaning (Geels, 2010). Regarding smart grids, actors also face many obstacles. There is still great uncertainty about the future evolution of the smart grid sector, and about how smart grids will evolve (Verbong et al., 2013), leading to a reluctance to invest (Tricoire, 2015). Moreover, some incumbents oppose the energy transition. Users' daily lives are influenced by the new technology: its adoption requires drastic changes in both user behavior and society (Van Der Schoor \& Scholtens, 2015). To overcome these challenges and to build a new ecosystem, smart-grid actors closely collaborate in system-building networks.

In the Netherlands, firms along the energy value chain, research institutes, government actors and user groups are working hard to develop and implement smart grid technology. These actors form various networks with different constellations and different aims, for example testing full-scale smart grid concepts in practice, or standardizing or accelerating smart grid development and implementation (Planko et al., 2016). With these activities, such system-building networks aim to build a new business field with the smart grid technology at its core.

The phenomenon of system-building networks has been observed particularly in relation to sustainability transitions (Musiolik \& Markard, 2010). Insights from sustainability transitions are very useful for understanding the emergence of new business fields and for bringing innovations to the market (Knight et al., 2015; Möller, 2010).

\section{Key factors of effective network management: proposal of a conceptual framework}

Network management is defined as the tools and strategies used to manage a deliberately established inter-organizational collaboration in order to achieve its common goal (Klijn, Steijn, \& Eldenbos, 2010; Milward \& Provan, 2003b). It differs from organizational management, as networks have no organizational hierarchy and managers cannot apply the command-and-control mechanisms that are widely used within organizations. Instead, networks need to be managed in collaborative, non-hierarchical ways (Dooley \& O'Sullivan, 2007; McGuire, 2002; Milward \& Provan, 2006). The management of inter-organizational networks has been studied in many different, often overlapping fields and from different perspectives (Möller \& Rajala, 2007), including industrial and business networks, strategic networks, innovation networks, and whole networks (Dhanaraj \& Parkhe, 2006; Gulati, Nohria, \& Zaheer, 2000; Klijn et al., 2010; Milward, Provan, Fish, Isett, \& Huang, 2009; Möller \& Rajala, 2007). These studies have been conducted in very different empirical contexts but can be used to develop theory on network management of inter-organizational networks (Järvensivu \& Möller, 2009).

For system-building networks, the literature on goal-directed networks is most relevant, particularly the literature on strategic networks. Within this literature stream, the literature on emerging business nets and especially on innovation networks - is most pertinent. Emerging business nets are future-oriented networks composed of actors aimed at developing new technologies, products and business models, or even creating new business fields. These actors strive for radical, 


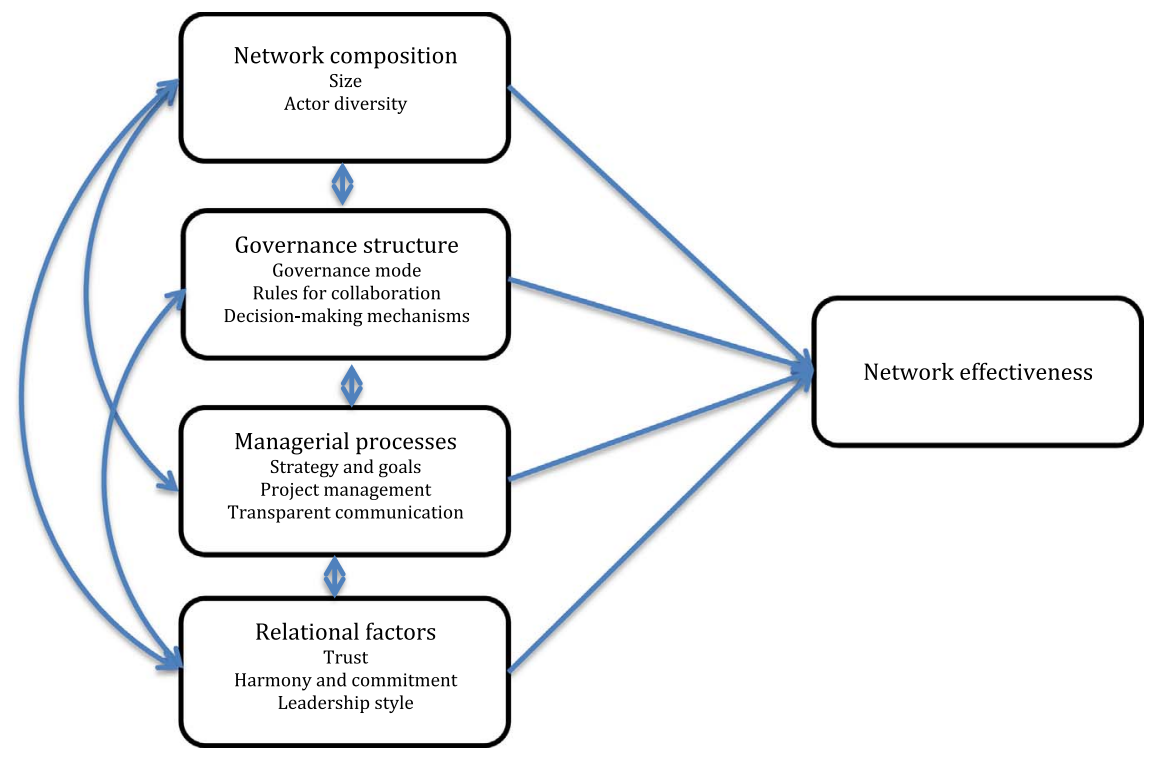

Fig. 1. Proposed network management framework: key factors of network management (creation of the authors, key factors based on literature review, clustering by authors). discontinuous and system-wide change; they operate under great uncertainty and their value-generation potential may only be fully realized in the future (Möller \& Rajala, 2007; Möller \& Svahn, 2003, 2006). The literature on emerging business nets does not yet include an overview of key factors of effective network management to achieve system benefits. Some research has been conducted in established industries on how to manage or orchestrate whole networks at the network level (Provan et al., 2007; Turrini et al., 2010). However, these insights have not yet been tested for networks in emerging business fields.

In the following sections, we define network effectiveness and subsequently give an overview of the key factors of effective network management.

\subsection{Network effectiveness and its key factors}

According to Rampersad et al. (2010), the most important outcome of network management is network effectiveness, which is defined as attaining positive network-level outcomes that could not normally be achieved by individual organizational participants acting independently (Provan \& Kenis, 2008). Other authors define network effectiveness as (1) the actual or perceived ability to reach predetermined network goals (Turrini et al., 2010; Weiss, Anderson, \& Lasker, 2002), (2) the perceived outcomes of network management strategies (Klijn et al., 2010), (3) the degree to which network collaborations are successful (Rampersad et al., 2010), or (4) the net's capability to invent and produce solutions that provide markets with more value than existing offerings (Möller \& Svahn, 2003). Based on these definitions, we define network effectiveness as the perceived attainment of positive networklevel outcomes with regard to reaching predetermined network goals.

To manage a network effectively, a number of key factors should be in place. Such key factors are elements that enhance network effectiveness (Rampersad et al., 2010; Thorgren, Wincent, \& Örtqvist, 2009). They are usually intertwined and influence each other (Klijn et al., 2010; McGuire, 2002), and together they enable the network to reach its goals, i.e. they contribute to network effectiveness. We identified key factors from the literature that contribute to effective network management at the network level and that are relevant for the management of networks in emerging business fields. We found that some factors are characteristics of the network whereas others are processes that enhance these characteristics. For example, some authors classify 'trust' as a characteristic while others regard 'trust building' as a managerial process. In order to make networks effective, managers have to create favorable conditions in which network actors can achieve positive network outcomes (Rusanen, 2013). We therefore decided to categorize the identified factors by network characteristics, as 'favorable conditions that need to be established'. Network goals can best be reached if these characteristics (e.g. trust) are in place. This, of course, needs to be organized and managed (e.g. trust building). We imply that managers strive to achieve these network characteristics by carrying out the relevant processes.

It was difficult to use an existing classification to merge the identified key factors because each author had chosen slightly different categories. Since we use key factors from different literature streams, some of the factors we identified would not fit into the existing categories. As Ritter et al. stated, "the problem with today's body of relationship and network literature is that it is fragmented and different pieces do not seem to fit together" (Ritter \& Gemünden, 2003a, 2003b, p. 692). Therefore, we generated our own classification, which included sufficient categories to classify all the key factors but not too many categories, as this would make categorization less useful.

We have clustered the key factors of network management into the following four categories: network composition, governance structure, managerial processes and relational factors. Network composition involves the structural factors regarding the composition of the network. Governance structure comprises the structural characteristics that influence network governance. The cluster managerial processes contains the process factors, i.e. the core network management functions. The category relational factors comprises the personal and interpersonal factors (or 'soft factors') that influence network effectiveness. The categories and their key factors are explained below. A conceptual framework of all key factors is shown in Fig. 1.

The key factors of network management described below can be and often are - interrelated. Network management input, managerial behavior and their outcomes influence each other (Freytag \& Ritter, 2005; Klijn et al., 2010; Turrini et al., 2010). For example, a high level of trust increases harmony and reduces formalization (Milward \& Provan, 2003a; Rampersad et al., 2010), and aligned network goals may increase commitment (McGuire, 2002; O'Toole, 1997; Provan \& Kenis, 2008). We are aware of this interrelatedness and take this into consideration when necessary. In Fig. 1 the interrelatedness of key factors is visualized by arrows connecting the key factors. Of course, other factors also influence the realized network effectiveness, such as uncertainty, the complexity of goals and tasks involved, and the knowledge level of available network members. Since our interest is in network management, we focus on key factors related to network management. 


\subsection{Network composition}

The two main factors of network composition are size and actor diversity (Russell, Meredith, Childs, Stein, \& Prine, 2015; Turrini et al., 2010). An effective network should be large enough to carry weight but not too large to manage or to have a common goal. Depending on the network goal, there may need to be more actor diversity, i.e. more diversity in resources and abilities (Ojasalo, 2008; Thorgren et al., 2009). To a large extent, the composition of the network is decided at the start. When networks are already in place, their composition may still be influenced by the inclusion and removal of members (Möller \& Rajala, 2007; Partanen \& Möller, 2012; Ritter \& Gemünden, 2003b) and by keeping members committed (McGuire, 2002).

\subsection{Governance structure}

Governance structure includes the network's governance mode, rules and decision-making processes. These structures are often determined at the network design phase but then adjusted at different network stages (Raab, Mannak, \& Cambré, 2013; Russell et al., 2015).

\subsubsection{Governance mode}

Strategic management of the network involves the establishment of a formal organization containing all the net members involved (Möller \& Rajala, 2007). The appropriate governance mode for networks depends on several factors, including size, goals, task and trust (Provan \& Kenis, 2008). For small networks, the self-governing form may be appropriate, where network members collectively make both strategic and operational decisions about how the network operates, without formal governance (Provan et al., 2007). However, if the network grows, this mechanism may become inadequate (Milward \& Provan, 2006).

Most network management authors reason that networks should be coordinated by a single entity. For example, Rampersad et al. state that "[a] single coordinating body is necessary to ensure continuity and the achievement of network objectives" (Rampersad et al., 2010). This coordinating entity may be an appointed network manager, an elected board, a hub firm or a network administrative organization (Dhanaraj \& Parkhe, 2006; Turrini et al., 2010). For innovation networks, the existence of a network manager is often presented as the best option (Heidenreich et al., 2016; Landsperger, Spieth, \& Heidenreich, 2012). The network manager directs network processes, acts as an indispensable central node, arranges, moderates and mediates meetings, resolves disputes, sets goals, creates an atmosphere of harmony and trust, and provides incentives to cooperation (Agranoff \& McGuire, 2001; Turrini et al., 2010). Moreover, the network manager has decision-making powers and represents the network to the outside world (Landsperger et al., 2012; McGuire, 2002). Network managers greatly influence network effectiveness: they mobilize network resources and much vital information passes through them. In particular networks with high actor diversity that operate in complex environments - such as system-building networks - benefit from a network manager (Heidenreich et al., 2016).

\subsubsection{Rules, agreements and decision-making mechanisms}

For networks to function effectively, clear cooperation agreements and formalized rules for collaboration need to be established and implemented (Agranoff, 2006; Partanen \& Möller, 2012; Turrini et al., 2010). Rules and agreements may be formal or informal. The higher the level of trust in a network, the lower the need for formalized rules and contracts (Ojasalo, 2008). Formalization increases precision and fairness, but too much formalization leads to inflexibility and rigidity (Choi \& Hong, 2002).

Furthermore, decision-making processes should be shared and equitable (Agranoff \& McGuire, 2001; Spieth, Clauss, \& Landsperger, 2011). As network members are partners rather than superiors and subordinates, they reach agreement by consensus rather than by imposing decisions (Möller \& Rajala, 2007). Voting rules are often part of the by-laws, but voting usually only takes place after agreement has been reached or as a last resort (Agranoff, 2006; McGuire \& Agranoff, 2011).

\subsection{Managerial processes}

Coordination of tasks and activities at the network level is necessary for network effectiveness; activities need to be orchestrated (Dhanaraj \& Parkhe, 2006; Möller \& Svahn, 2003; Paquin \& HowardGrenville, 2013). While influencing the network structure and composition, network managers also need to direct network processes, create optimal conditions for collaboration, and contribute to maximal performance (Chesbrough \& Appleyard, 2007; Järvensivu \& Möller, 2009). Adequate management mechanisms ensure that network outcomes are achieved (Ojasalo, 2008; Rampersad et al., 2010; Ritter et al., 2004). The more integrated and coordinated the network is, the more effective it will be (Milward \& Provan, 2003b). Although it should be mentioned that too tight coordination may turn the network into a hierarchy, which reduces innovativeness and flexibility (Håkansson \& Ford, 2002). The solution to this 'network paradox' is a combination of strategic level network leadership, jointly developed goals and operational level coordination (Möller \& Svahn, 2003, 2006). Below we elaborate on three important factors related to managerial processes.

\subsubsection{Strategy and goals}

To manage networks effectively, an overall strategy needs to be developed at the network level (Klijn et al., 2010; Ojasalo, 2008; Ritter \& Gemünden, 2004). This strategy development includes the development of a vision and a clear mission, the setting of goals and common objectives, as well as a clear definition of deliverables (Agranoff, 2006; Möller \& Svahn, 2003; Turrini et al., 2010). This helps the effective allocation of resources towards network goals (Spieth et al., 2011). Agenda setting, developing a systemic view of the business field, and envisioning the development pathway of the new business field mobilizes actors, reduces uncertainty and provides direction for action (Möller, 2010; Möller \& Rajala, 2007). Network participants are more likely to be involved and committed to the network if there is general consensus on broad network-level goals (Provan \& Kenis, 2008).

Over time, network objectives need to be adapted according to changes in the external environment (Turrini et al., 2010).

\subsubsection{Project management}

The strategies described above also need to be implemented (Ojasalo, 2008; Ritter et al., 2004). To achieve the network goals, the network has to be managed as a project (Dhanaraj \& Parkhe, 2006; Möller \& Rajala, 2007). For example, administrative systems and processes need to be in place and network members need to be motivated (Page, 2003; Turrini et al., 2010), and regular meetings need to be organized with written agendas provided in advance (Heidenreich et al., 2016; Spieth et al., 2011; Turrini et al., 2010). In fact, the regularity of network gatherings is one of the main stabilizing factors (Spieth et al., 2011). Part of managing the network is to distribute tasks among the network members, to determine who is responsible for what, and to establish how to respond to free-riders (Milward \& Provan, 2006; Partanen \& Möller, 2012; Ritter et al., 2004). This is especially challenging in networks, due to the lack of a chain of command (Milward \& Provan, 2006). The performance of the network and its members as well as network progress should be measured and evaluated, in order to ensure the effective use of resources (Raab et al., 2013; Ritter et al., 2004; Turrini et al., 2010).

\subsubsection{Transparent communication}

Another key factor of network management is clear and transparent communication (McGuire, 2002; Spieth et al., 2011). This includes the 
provision of all necessary information to all participants, enhancing information exchange between participants, and regular and transparent documentation of the network's progress (Heidenreich et al., 2016; Rampersad et al., 2010; Ritter et al., 2004). Transparent communication facilitates information flows and information capture, thus making networks more effective. Transparency can be increased with electronic tools, such as online interaction platforms (e.g. exchange forums and web-based team rooms), web-based information systems, and formal communication channels such as email and teleconferencing (Dhanaraj \& Parkhe, 2006; Heidenreich et al., 2016; Turrini et al., 2010).

\subsection{Relational factors}

The last cluster of key factors summarizes so-called 'soft factors', which are based on culture and norms as well as the behavior of network actors. These factors influence the atmosphere in the network and thus its outcome (Dhanaraj \& Parkhe, 2006; Heidenreich et al., 2016).

\subsubsection{Trust}

Trust is defined as "confidence in an exchange partner's reliability and integrity" (Rampersad et al., 2010). It is considered the main mechanism behind the dynamism of networks, making networks more efficient and effective (Heidenreich et al., 2016; Ozman, 2009). The more trust there is in a network, the greater the ability to accomplish network goals (Milward \& Provan, 2006). It is important that network managers develop trust and understanding between network members (Milward \& Provan, 2006; Raab et al., 2013; Ritter et al., 2004). Trust can be built by having frequent high quality face-to-face interactions, by exhibiting frankness, by keeping promises, and through clear, predetermined sanctions for trust violation (Milward et al., 2009; Ozman, 2009; Rampersad et al., 2010). Moreover, trust is seen as a complement to or substitute for governance mechanisms. The higher the level of trust, the less control and the fewer written agreements needed, thus reducing governance costs (Ojasalo, 2008; Provan et al., 2007; Rampersad et al., 2010) and increasing network effectiveness.

\subsubsection{Harmony and commitment}

Another key factor in network management that refers to the relationship between participants is harmony. A higher level of harmony increases network effectiveness. Harmony is described as an understanding of give and take, and a preparedness to acknowledge each other's viewpoints (Heidenreich et al., 2016; Spieth et al., 2011). This level can be increased by developing mutual interests among network members, by involving actors in the planning and coordination of activities, and by addressing and managing conflicts (Provan \& Kenis, 2008; Rampersad et al., 2010).

Furthermore, the level of commitment from members must be sufficiently high to attain network-level goals. Network members must allocate resources and staff to the network. In the absence of a hierarchy, they must voluntarily devote their time and skills to network tasks (Dhanaraj \& Parkhe, 2006; Milward \& Provan, 2006; Turrini et al., 2010). Moreover, the loss of members would decrease the dynamic stability of the network and would lead to a loss of knowledge, skills and resources. Therefore, an important task of network management is building and maintaining the commitment of all network members, especially of critical ones (Järvensivu \& Möller, 2009; Milward \& Provan, 2006).

\subsubsection{Leadership style}

Whereas governance mode and coordination mechanisms are significant factors in network management, even more important than the organizational structure is the management quality (Klijn et al., 2010; Milward \& Provan, 2006). In contrast to managers in organizations, network managers cannot exert top-down authority or command action. Nevertheless, they are responsible for the network output (McGuire, 2002; Turrini et al., 2010). Therefore, a specific type of leadership is necessary for network management, in which the principle of 'soft guidance' is required as a replacement for command-and-control. The network manager should adopt a synchronizing, enabling role, direct participative decision-making processes, and act as an impartial manager. He should inspire and motivate others to form a common vision and to freely engage in network tasks (Agranoff \& McGuire, 2001; Landsperger et al., 2012). The ideal network manager should possess high levels of authority as well as functional and task competence; moreover, he needs methodological competences similar to those of a project manager (Landsperger et al., 2012).

\subsection{Summary}

Table 1 summarizes how the key factors of network management described above should be implemented at the network level in order to

Table 1

How key factors should be implemented to have a positive influence on network effectiveness.

\begin{tabular}{|c|c|}
\hline Key factors of network management & How key factors should be implemented to increase network effectiveness \\
\hline \multicolumn{2}{|l|}{ Network composition } \\
\hline Size & Depends on network's aim: large enough to have influence but small enough to be manageable. \\
\hline Actor diversity & Depends on network's aim: higher diversity means more resources and capabilities but also more conflict potential. \\
\hline \multicolumn{2}{|l|}{ Governance structure } \\
\hline Governance mode & Different modes possible. Important to have a single coordinating body (organization or leader) in charge. \\
\hline Rules for collaboration & Clear cooperation rules necessary. Formalization increases fairness but too much formalization leads to inflexibility. \\
\hline Decision-making mechanism & Important to have consensus decisions (participative and equitable decision-making). \\
\hline Network leadership structure & Assigned network manager contributes to better coordination and information flows within network. \\
\hline \multicolumn{2}{|l|}{ Managerial processes } \\
\hline Strategy and goals & Clear vision and common goals necessary to reach network objectives. Goal-alignment leads to higher effectiveness. \\
\hline Project management & $\begin{array}{l}\text { Good project management (regular meetings, written agendas, administrative systems) necessary to keep members motivated and to } \\
\text { achieve network goals. Measuring and evaluation ensures effective use of resources. }\end{array}$ \\
\hline Task distribution & Determine who is responsible for what. Requires clear deliverables. \\
\hline Transparent communication & Clear and transparent information exchange between all members increases information flow and information capture. \\
\hline \multicolumn{2}{|l|}{ Relational factors } \\
\hline Trust & Higher trust level increases ability to accomplish network goals. \\
\hline Harmony and commitment & High level of commitment and harmony necessary for members to contribute time and resources to network. \\
\hline \multirow[t]{4}{*}{ Leadership style } & Network effectiveness depends heavily on good network leader. \\
\hline & Participatory leadership style necessary. \\
\hline & Leader should adopt synchronizing, enabling and impartial role. \\
\hline & Ideal network manager should possess functional and task competence as well as project management competences. \\
\hline
\end{tabular}


increase network effectiveness. We use it as a conceptual framework for our empirical study of the system-building networks in the smart grid sector.

\section{Method}

We adopted a case study approach, as was suggested by Choi \& Hong for conducting research in an emerging business field (Choi \& Hong, 2002). This was a multiple-case study (Yin, 2009) in the Dutch smart grid sector to help understand how system-building networks are managed effectively.

The first step was the identification of networks operating in the Dutch smart grid sector. In a pre-study we identified the national networks that established the Dutch smart grid field. We did so by asking key actors, e.g. spokespersons at national smart grid conferences and smart grid experts from industries and research institutes. The outcome was a list of six networks that work towards different aspects of collective system building (e.g. lobbying for suitable regulation, working towards standardization, and developing and optimizing technology). Each of the networks is described in more detail in Section 6.1. Together, these networks form the Dutch smart grid sector. Möller and Svahn (2003) state that a business field consists of several overlapping strategic networks, and the Dutch smart grid field comprises these six overlapping strategic networks. The actors of our researched networks are often also members of one or more other networks, which makes the Dutch smart grid field a suitable industry for analyzing the key factors of the network management of system-building networks. Table 2 gives a brief overview of these networks.

The next step was data collection on the different networks. We interviewed 3-4 key actors from each network: the network managers and chairmen, as well as members of the board of directors. We stopped interviewing more actors when we found our data was saturated for the network. Table 3 gives an overview of our interview partners, their network, and their role in this network. In the results section, we refer to the interviewees by their numbers in squared brackets, e.g. [1] indicates that the quotation is from interviewee 1 , who is the network manager of network C. As can be seen from the table, some of our interview partners were members of two or more networks and were thus able to provide insight into these networks.

The interviews were semi-structured and were conducted face-toface. Each interview took 60-100 min. Our interview guide was based on the key factors identified from the literature. In addition, we checked how the interviewees perceived the influence of these key factors on network management outcomes and whether they mentioned additional key factors. We based our method on van der Valk, Chappin, and Gijsbers (2011), who asked interviewees about the way in which the network is managed, to derive implications for management, and on Rampersad et al. (2010), whose "level of theory and analysis is the net while measurement is carried out by surveying multiple key informants within each network organization while retaining focus on net issues" (p. 795). In the interviews we also asked about network effectiveness. In line with previous research (e.g. Klijn et al., 2010; Provan et al., 2007; Turrini et al., 2010), we measured network effectiveness by asking network members about the perceived success in reaching network goals. As a final step in the data collection, we triangulated our interview data by studying network websites and strategy documents found on these websites or provided to us by interview partners.

All interviews were transcribed and analyzed using Atlas.ti software. We coded the data according to the key factors of network management derived from the literature review. If no pre-defined code was suitable, new codes were added. We first conducted an in-depth analysis of each network, identifying how the different key factors were implemented and in what way the key factors contributed to the effectiveness of that specific network. Then we conducted a cross-case analysis, to look for patterns across networks. Subsequently, we compared findings per key factor of network management. This helped us gain insight into the influence on network effectiveness for each of the key factors. As discussed in Section 3, we were aware that the key factors of network management may be interrelated. Therefore, we also considered the interrelatedness of key factors when it was indicated in the interviews how they influenced each other. Finally, these results enabled us to compare our empirical observations with the conceptual framework.

\section{Findings}

First, we briefly introduce the six system-building networks in the Dutch smart grid sector. Then we compare our findings per key factor with the conceptual framework that we established based on our literature review. In addition, we depict how the key factors are implemented at the network level in networks building a new business field: the Dutch smart grid field.

\subsection{Brief case descriptions}

We briefly describe the six networks below, with regard to their objectives and perceived success.

\subsubsection{Network A: 'Testing \& Development'}

'Testing \& Development' was initiated by firms wanting to develop advanced smart grid technologies and services to secure an affordable and reliable energy supply and to enable end-users to control their own renewable energy management in an uncomplicated way. The network was founded with the aim of large-scale demonstration through several pilot projects and to test and develop smart grid technology. Network members collaborate with actors all along the value chain, including end-users. Twelve firms cooperate in five large-scale pilot projects to develop, test and optimize smart grid technology, using open innovation. 'Testing \& Development' is perceived as relatively successful. Pilot projects were conducted well and generated much valuable knowledge. Not all the initial ambitions were met, but actors realize that their ambitions had been too high at the beginning, and unrealistic in hindsight.

\subsubsection{Network B: 'Standardization Framework'}

'Standardization Framework' is a spin-off of 'Testing \& Development'. A few companies of 'Testing \& Development' realized that they wanted to accelerate standardization, but that this was less important to other members. To achieve their goal of standardization sooner, they decided to form an additional network, 'Standardization Framework'. To accelerate the development of commercially viable offerings based on its new standard, the network develops specifications and guidelines that enable companies to develop complementary smart energy products, services and solutions. 'Standardization Framework' is a partnership of seven firms: energy suppliers, network operators, electrical equipment manufacturers, consultancies, and IT companies. The members perceive the network as successful. A draft version of the standard has been produced. There is much interest in the framework from companies, also internationally.

\subsubsection{Network C: 'Device Standardization'}

'Device Standardization' was initiated by private firms together with a research institute in order to develop a standard. ${ }^{1}$ This new open standard enables the connection of household devices with energy management services. The standard can be built into devices and energy management services of different manufacturers, and it enables the devices to work together as a team - for instance to decide whether

\footnotetext{
1 Both 'Standardization Framework' and 'Device Standardization' work on standardization but on different parts of standardization within the smart grid system. They complement each other. The networks have signed an 'agreement of understanding', indicating that they accept and respect each other's standardization efforts.
} 
Table 2

Overview of the researched networks and their system-building objectives.

\begin{tabular}{|c|c|c|}
\hline Network & System-building objective & Number of participants \\
\hline A - Testing \& Development & Testing technologies + knowledge development + feedback loops with user groups & 3 \\
\hline B - Standardization Framework & Standardization, to accelerate the development of commercially viable offerings & 3 \\
\hline C - Device Standardization & Standardization, to enable household devices to easily connect with energy management services & 3 \\
\hline D - Industry Association & Infrastructure development + lobbying for legislation supporting the new technology & 3 \\
\hline E - Product \& Service Development & Development of commercially viable products + business model generation & 4 \\
\hline F - Knowledge Exchange & Sector-wide knowledge exchange + collaboration with government (to create enabling environment) & 4 \\
\hline
\end{tabular}

Table 3

Roles and network membership of interviewees.

\begin{tabular}{llll}
\hline Interviewee number & Network & Role in network & Case letter \\
\hline 1 & $\mathrm{C}$ & Network manager & $1 \mathrm{C}$ \\
2 & $\mathrm{~F}$ & Network manager & $2 \mathrm{~F}$ \\
3 & $\mathrm{E}$ & Network manager/chairman & $3 \mathrm{E}$ \\
4 & $\mathrm{E}$ & Member & $4 \mathrm{E}$ \\
5 & $\mathrm{E}$ & Network manager/project & $5 \mathrm{E}$ \\
& & manager & \\
6 & $\mathrm{E}$ & Member & $6 \mathrm{E}$ \\
7 & $\mathrm{D}$ & Network manager & $7 \mathrm{D}$ \\
8 & $\mathrm{~F}$ & Member (project leader of a pilot & $8 \mathrm{FA}$ \\
& & project) & \\
8 & $\mathrm{~A}$ & Member & $8 \mathrm{FA}$ \\
9 & $\mathrm{~A}$ & Network manager/project & $9 \mathrm{~A}$ \\
& & manager & \\
10 & $\mathrm{~B}$ & Network manager & $10 \mathrm{~B}$ \\
11 & $\mathrm{~B}$ & Member & $11 \mathrm{BA}$ \\
11 & $\mathrm{~A}$ & Member (former network & $11 \mathrm{BA}$ \\
& & manager) & \\
12 & $\mathrm{C}$ & Member (program line leader) & $12 \mathrm{CD}$ \\
12 & $\mathrm{D}$ & Member & $12 \mathrm{CD}$ \\
13 & $\mathrm{C}$ & Member (program line leader) & $13 \mathrm{CF}$ \\
13 & F & Member & $13 \mathrm{CF}$ \\
14 & B & Network manager/chairman & $14 \mathrm{~B}$ \\
15 & $\mathrm{D}$ & Member & $15 \mathrm{D}$ \\
16 & $\mathrm{~F}$ & Member & $16 \mathrm{~F}$ \\
\hline & & &
\end{tabular}

to use, store or sell locally produced energy, or to determine which device should be switched on first. On a smartphone or tablet, users can set their energy preferences, by turning devices on and off, or up and down whenever they want. This results in significant cost savings for consumers. Members of this network include seven firms and a research institute. The network is perceived as relatively successful by its participants and has received international recognition for its expertise and the standard that was developed. However, the actual implementation of their standard is taking longer than was hoped - the network still needs to grow, both nationally and internationally.

\subsubsection{Network D: 'Industry Association'}

'Industry Association' is a network with only grid operators as members, but with close connections to other stakeholders. It was set up many years ago and aims at representing the interests of its members and at conducting lobbying activities. Moreover, it is leading the 'Action plan sustainable energy provision 2030'. The network has a chairperson who represents the network externally and who manages the network's administrative organization. This organization has 16 staff members and is financed by its member firms via membership fees. The members perceive 'Industry Association' as successful. It is wellorganized and seen as a good platform for exchanging knowledge and experiences. As it is recognized and known by influential actors such as ministries, it is also successful at lobbying.

\subsubsection{Network E: 'Product \& Service Development'}

'Product \& Service Development' was initiated by public actors. The Dutch government wants to enhance the strength of the Dutch smart grid sector, so as to excel worldwide. Therefore, it initiated this collaboration of government, companies, universities and research institutes. The network aims at developing and launching innovative products and services in the smart grid field. Moreover, it wants to orchestrate and support the development of the smart grid ecosystem. The network is perceived as very successful, and actors are content with the way the network is organized and with its intermediary outcomes. Not only has the network created much awareness, but it has also established a procedure for different parts of the smart grid ecosystem.

\subsubsection{Network F: 'Knowledge Exchange'}

'Knowledge Exchange' is a public-driven network. Its objective is to accelerate the introduction of smart grids by stimulating collaboration of relevant actors on both national and regional levels, by diffusing knowledge, and by creating positive conditions for the implementation of the technology. A governmental agency manages this network on behalf of the Dutch Ministry. 'Knowledge Exchange' differs considerably from the networks described above. While it conforms to the definition of strategic networks, it is actually a program initiated by the government, with the aim of increasing knowledge transfer and demonstrating that smart grids are a suitable technology to foster the energy transition. The network has more than 100 member firms and research institutions, which participate in one of the 12 pilot projects. Each pilot project has a representative who reports back to the network manager. The pilot projects are only connected to each other through the network manager, who functions as the central node. The network is seen as relatively successful, in terms of connecting a wide range of actors in the field, stimulating knowledge exchange and demonstrating the usefulness of smart grids.

All networks were perceived successful or relatively successful in reaching their intermediary objectives. Table A.1 (Appendix 1) shows an overview of the key factors of network management per network.

\subsection{Empirical evidence on key factors of network management at the network level}

Table 4 shows a brief overview of the key factors, how they should be implemented to increase network effectiveness based on literature, and the observations we made regarding the effects on the perceived effectiveness of these key factors in the networks we studied.

Below we elaborate on each of the key factors and on how the managerial practices used influence the perceived network effectiveness. We illustrate our observations with selected examples from the networks we studied. The single-case analysis (Appendix 1) indicates that there are many similarities between the networks. To avoid repeating results that are similar in all networks, we instead describe the key factors for all groups and highlight the differences between certain networks or describe specific conditions in which different types of managerial practices were used.

\subsubsection{Cluster network composition}

The networks studied differ in size and actor diversity. Depending on the goal of the network, it is more desirable to have a smaller or larger network. For example, for the network 'Knowledge Exchange', the goal is industry-wide knowledge exchange. Therefore, a large network composed of diverse actors is desirable. 'Device Standardization', 
Table 4

Conceptual framework of key factors and observed effects on perceived network effectiveness.

\begin{tabular}{|c|c|c|}
\hline $\begin{array}{l}\text { Key factors of network } \\
\text { management }\end{array}$ & $\begin{array}{l}\text { How key factors should be implemented to increase network } \\
\text { effectiveness }\end{array}$ & $\begin{array}{l}\text { Observed effects on perceived network performance (detailed description in } \\
\text { text below) }\end{array}$ \\
\hline
\end{tabular}

Network composition

Size

Actor diversity

Governance structure

Governance mode

Different modes possible; important to have a single coordinating body (organization or leader) in charge.

Rules for collaboration

Decision making mechanism

Network leadership structure

Managerial processes

Strategy and goals

Clear cooperation rules necessary. Formalization increases fairness but too much formalization leads to inflexibility. Important to have consensus decisions (joint and equitable decision-making)

Assigned network manager contributes to better coordination and information flows within network.

Clear vision and common goals necessary to reach network objectives.

Goal alignment leads to higher effectiveness.

Project management

Good project management (regular meetings, written agendas, administrative systems) necessary to keep members motivated and to achieve net goals.

Measuring and evaluation ensures effective use of resources. Determine who is responsible for what. Requires clear deliverables.

Clear and transparent information exchange between all members increases information flow and information capture.

Relational factors

Trust

Higher trust level increases ability to accomplish network goals.

Harmony and commitment

High level of commitment and harmony necessary for members to contribute time and resources to network.

Leadership style
Network effectiveness depends heavily on good network leader. Participatory leadership style necessary. Leader should adopt synchronizing, enabling and impartial role. Ideal network manager should possess functional and task competence as well as project management competences.
Smaller size increases effectiveness; larger size may be necessary to link all players in sector for information flow/transparency, but this diminishes the exchange of vital information.

Depends on network's aim. Diversity necessary for most aims. Diversity does not necessarily increase conflict potential. Higher actor diversity may also mean that there is less direct competition which facilitates exchange of vital information.

Preferred mode: board of directors and then working groups who report back. Single coordination body necessary; consisting of network members; top-down approach not considered as effective (but may be necessary for sector-wide network which increases transparency).

Clear rules necessary. Trust is better than much formalization. Very clear boundaries set for information sharing as enabler for collaboration. Discussion till consensus (A-E) considered most effective. Top-down decision-making not appreciated by network members.

Mostly two network leaders, rather than one. One content specialist and one project manager.

Jointly created vision and goals help to motivate members and give direction; if not jointly created, goals entail less motivation. Goal-alignment (firms-to-network) leads to higher effectiveness. Frequent goal-adjustment necessary in quickly changing environment Goal-adjustment and goal-alignment influence network composition. Good project management vital to keep members motivated, as financial benefits lie in future and membership is voluntary.

Measuring and evaluation perceived important but proves difficult in uncertain, fast-changing environment.

Participatory distribution (ask who volunteers for a task or who would be most suitable).

Perceived as very important; electronic tools used such as website, platform, emails; provision of all information to all members.

Trust seen as major factor for network effectiveness, especially because members have to share vital information.

High level of trust decreases governance costs and facilitates collaboration and knowledge exchange.

Selecting individuals when composing network increases trust level.

Goal-alignment increases harmony and commitment.

High trust (hand-picked members) increases harmony.

Network management style increases harmony and commitment.

Leadership quality has high impact on network effectiveness.

Participatory leadership style increases motivation.

Neutral leader decreases fear of opportunistic behavior.

Content-specialist necessary to chair meetings and represent network externally.

Person with project management skills necessary to ensure good process management and high member motivation.

Two or three leaders necessary, often an external person (non-network member) is hired to fulfill one of these roles. which aims to develop a standard for smart grid applications, deliberately started small so that the goal, a common standard, could be reached. 'Industry Association' is an example of a network with homogeneous actors, as it is an industry association. By contrast, 'Testing \& Development' consists of members all along the energy supply chain, which is necessary to develop and optimize innovative products for end-users. The multiple-case study showed that the most suitable composition of the network in terms of size and diversity depends on the network's system-building goal.

The network composition needs to be adjusted over time, as a result of goal adjustment or goal alignment. For example, 'Device Standardization' had been founded by three organizations. The small size was beneficial in the initial phase of the network, because the goal of the network was to produce a standard, and according to the interviewees it is easier to develop a standard with fewer organizations. One of the organizations is a research institute that made sure that the developed standard would be beneficial to many companies, not only for those directly involved. For the next step, the rollout of the standard, more member firms are necessary.

With regard to stability, there was a remarkable finding in 'Testing \& Development'. This network started with great ambition, resulting in a situation that "ambitions were higher than activity within the network" [10]. Some members were more ambitious than others, which led to conflicts and temporary stagnation. Asking companies to invest a substantial membership fee into the network solved this problem: only the companies that were really interested and ambitious invested, and the less interested firms decided to leave. This led to a decrease both in the size of the network and in the number of pilot projects. However, it strengthened the network and enabled it to achieve its goals.

\subsubsection{Cluster governance structure}

5.2.2.1. Network governance structure and leadership. Networks A-E 
have a similar governance structure. They have a board of directors that takes the most important decisions and which consists of 4-12 members, depending on the network. Moreover, they have workgroups, pilot projects or program lines which report back to the board of directors. Strategic decisions are taken during meetings of the board of directors. Furthermore, there are usually two network leaders who steer and orchestrate network activities. The networks 'Testing \& Development', 'Standardization Framework', 'Device Standardization' and 'Product \& Service Development' have two network leaders: a chairman, who is a technical expert and responsible for the content and who acts as spokesperson of the network, and a project manager, who directs the network processes. This role separation can be illustrated by the network 'Standardization Framework'.

'Standardization Framework' has two leaders: a chairperson, who is an employee of one of the member firms, and a network manager from an external organization. The network deliberately employed an external network manager, someone with expertise and connections in the energy field who was not an employee of one of the member firms, to ensure and signal that this person was a neutral party, and not there to push his company's objectives. This neutrality was considered especially important as the objective of the network is to develop an industry-wide standard. The network manager directs the processes in the network and acts as a project manager with a participatory leadership style and expertise in developing group dynamics. The board is chaired by the network chairperson, who is in charge of the network's content. The chairperson is a technical expert and an employee of one of the member firms.

5.2.2.2. Financing mechanism. The financing mechanism of the networks seemed to be an important part of the governance structure. It influenced network composition (as described above), decisionmaking power as well as member commitment.

In 'Testing \& Development', there was some dissatisfaction about members putting more effort and resources into the network than others. This problem was solved by introducing a membership fee. Members had to invest a substantial sum of money into the pilot project. For some members this was a breaking point, and they left the network, causing the network to shrink to twelve members. However, the smaller size was perceived as positive; it contributed to the success of the network, as "only the motivated ones stayed" [8], and these remaining members worked hard on the project.

Networks 'Testing \& Development', 'Standardization Framework' and 'Industry Association' asked membership fees, and 'Device Standardization' expected financial contributions. By contrast, to participate in pilot projects of the network 'Knowledge Exchange', networks of firms were required to apply with a project plan; based on this, they received a first subsidy payment. Further payments were received when milestones described in the project proposal were achieved. This is the only network in which members receive money, instead of having to contribute money. The subsidy mechanism has been mentioned as one of the reasons why the network is not as successful as it could be.

5.2.2.3. Rules and decision-making mechanisms. Interview partners stated that they perceived the exact form of the chosen governance mechanism as less important for network effectiveness than having clear rules and decision-making mechanisms in place. Clear rules for collaboration are necessary to enable decision-making and knowledge sharing and to facilitate the collaboration processes. Within each system-building network, it is very clearly defined to which degree knowledge sharing is allowed within and outside the network. These clear boundaries actually enable the sharing of information.

In general, decisions were made at the highest possible level, and as few members as possible were involved in the decision-making process, to avoid these processes becoming too slow and too unclear.

To reach decisions, a general model can be observed. The chairperson or project leader provides the board members with relevant information prior to the meeting, so that they can make an informed decision. Managers prefer to receive tailored information, to better understand how the decision will benefit both their individual firm and the system in general. During board meetings, members discuss the decision to be taken, and in the end this always leads to consensus.

\subsubsection{Cluster managerial processes}

5.2.3.1. Strategy, goals, goal adjustment and goal alignment. To give direction to the activities of system-building networks, it was perceived important that a shared vision and mission was created jointly with all network members. To move towards this vision effectively, goals need to be set. In the fast-changing environment of the emerging smart grid sector, these goals need to be frequently adjusted to the changing environment. In networks A-E, members jointly determined vision and goals. There are two reasons why this was necessary. First, the key actors' input was required because of the high uncertainty on how the sector would evolve. Second, this ensured that company goals, which could be quite diverse within a network, would be aligned to the network's goals: either because members would make sure that the network goal was in line with their company's strategy, or because they would later try to align their long-term company strategy with the newly established network goal so that the company could reap future benefits from the new market.

An interesting mechanism for goal alignment was observed in 'Testing \& Development'. When this network started, it had 36 members and five pilot projects were set up. Goals and objectives were formulated and adjusted several times after the network was set up, which was necessary because at first nobody knew where the smart grid sector was heading or how the technology would evolve. Moreover, it turned out to be difficult to collaborate efficiently together with so many parties because member firms had different goals. Some goals turned out to be so different from the network goals that the members discontinued the collaboration and left the network. This was perceived as positive, because only the motivated firms stayed and as their goals were aligned, they all worked hard towards the network goals. Another goal-alignment mechanism was that some companies within the network realized that together they strived for a different goal than the defined network goal, leading to a spin-off of a sub-group of members. They formed the network 'Standardization Framework', while they remained members of 'Testing \& Development'; in the new network this smaller subgroup could work on their common goal with equally high levels of motivation.

5.2.3.2. Project management. Interviewees experienced project management as very important for the effective network management of system-building networks. System-building networks reap the benefits of their collaboration at a point much later in the future; in the present it is often still unclear what these benefits will be exactly. Therefore, meetings and interactions need to be well-organized to keep members motivated. Especially since network membership is voluntary (as opposed to participation in intra-organizational project groups), poor project management will lead to a decrease in commitment and motivation as well as an absence of members. After a meeting without a clear agenda, it is likely that only few members will attend the next one. "If they know a meeting will be well-chaired and useful, people don't feel like they are wasting their time." [11] Some interviewees stated that the quality of its project management can make or break a network.

5.2.3.3. Task distribution, incentivizing members and dealing with free riders. In networks we studied, tasks are distributed on a voluntary basis, according to members' skills and expertise. Participants are intrinsically motivated, members "like the challenge of solving a problem, of developing something that hasn't been there" [3]. Since command-and-control mechanisms cannot be used, the network manager should "arrange that things get done" [8]. This is achieved by 
personally addressing members and requesting they bring in their specific expertise. "Usually the most capable person for the task volunteers to do it." [10].

Network E experienced a single case of free-riding behavior: a member did not perform but received all the available information. Subsequently, the network manager had a private talk with the person concerned, who stepped down as a consequence.

5.2.3.4. Transparent communication. Interviewees described clear and transparent communication as an important key factor for network management. In a newly emerging sector, information is sparse and hard to attain, which makes it very valuable. All networks make use of electronic tools such as websites, email and teleconferencing. Moreover, they organize roadshows and networking events to increase information flows and connections among actors in the field. Several network managers mentioned that web-platforms for open innovation would enhance the information flow within the network and the sector, but so far such web-platforms have not yet been implemented.

\subsubsection{Cluster relational factors}

5.2.4.1. Trust. Networks A-E experienced high levels of trust, harmony and commitment. Trust was seen as a major factor for network effectiveness, particularly because actors in these networks have to share vital information about their business and their ideas in order to establish a compatible ecosystem. Most often trust is used as a governance mechanism taking the place of written agreements on IP rights. Drawing up written agreements for everything is seen as too costly and as hampering knowledge exchange. Since firms in the sector work in different constellations on different projects, it was often agreed that "what was developed or shared in the pilot project, stays in the pilot project" [13], meaning that members agreed not to share knowledge with other close partners. This clear definition of boundaries is based on trust. In some networks a level of trust was present from the start, when most of the firms had common collaboration experiences in previous projects. A remarkable trust-building mechanism was observed in network 'Product \& Service Development', in which trust was established by handpicking members. All 'active' network members (the board of directors) were hand-selected. The network manager selected some members he knew personally, and these suggested further members. From the first meeting on, the atmosphere was excellent and participants were highly motivated. There were high levels of harmony and trust in the network, and its members perceived it as very successful because of the high initial level of trust and harmony, which remained at a high level thanks to network leadership skills (see below).

5.2.4.2. Commitment, motivation and harmony. High levels of commitment and motivation could be reached in the networks if members realized they were contributing to a state-of-the-art solution to a problem, if they were given freedom to bring in ideas and expertise and if there was a high level of trust which enabled them to share these ideas and knowledge without having to fear opportunistic behavior from other members. A participatory leadership style and good project management helped to keep motivation and commitment high. Moreover, network members were intrinsically motivated because they wanted to contribute to the transition process. "Their drive and motivation is very high. It comes out of themselves, when they are together they all want to go faster." [10].

5.2.4.3. Leadership style. A network leader, someone who orchestrates the network, was seen as an important enabler of network success. "If you don't have somebody who stands up and says 'if you do this and you do that, then we achieve our goals much faster', people just keep walking around and don't get anywhere at the end of the day." [11] Interviewees preferred a participatory leadership style. "You don't want to have a dominant leader, but rather a strong and committed one." [6] "A top-down approach would absolutely not work. That's impossible." [7].

The network leader should be strict when it comes to time-management during meetings and make sure that a discussion ends in a decision, to increase the effectiveness of meetings. However, when it comes to task distribution and goal development, network members should always be asked for their opinions and be included in the process. "As a network leader you have to ask them questions. They themselves need to be in charge." [10] "I don't have any top-down authority on them. Of course I talk with them about what we are trying to achieve together, but then they have to take their own responsibility and make that happen." [7].

The importance of the leadership style can be illustrated by the example of network 'Product \& Service Development', the most successful network in terms of reaching its goals. The high motivation of the members of this network was attributed to the capabilities of the network manager, in addition to the high trust level. The manager of 'Product \& Service Development' has a very participatory leadership style. He directs the participants to reach decisions, but they are the ones taking the decisions. He does this so subtly that some of the interviewees even stated, "We do not have a leader. We do it all by ourselves." [4] This perceived freedom and power seems to be very motivating. All members work hard to achieve the self-defined network goals, and everyone is glad to bring in their own expertise.

\section{Discussion and conclusions}

First, we discuss key novel findings as compared to the literature. Then we highlight the theoretical implications as well as the managerial implications of our study. Finally, we point out the limitations of this study and ideas for future research.

\subsection{Discussion of findings and theoretical implications}

In this study, we introduce a special type of emerging business network into the network management literature: collective systembuilding networks. Collective system-building networks fall within the definition of emerging business networks as (1) they achieve common innovation goals, such as the joint development of products, services or processes, (2) they create so-called dominant technological designs to accelerate market construction by influencing public opinion, and (3) they generate commercially viable business applications out of the evolving technology (Möller \& Rajala, 2007). However, system-building networks have even more far-reaching goals, as they pro-actively aim to establish new business fields, and this has implications for the type of management they require (Järvensivu \& Möller, 2009; Möller \& Rajala, 2007). The existing network management literature turned out to be useful to study system-building networks. We first developed a framework for effective network management by identifying clusters of key factors of network management at the network level. The key factors were also applied in system-building networks. However, we observed some notable differences in the implementation of these key factors.

First, optimal network composition depends on the individual network's objective. This objective may change frequently in the fastchanging environment of the emerging smart grid sector, and the resulting changing network composition may be beneficial to the network. A decrease in network size can strengthen the network and enable it to achieve its goals. This is in contrast to the findings of most network management scholars, who see network stability as a major aim of the network (Freytag \& Ritter, 2005; Håkansson \& Ford, 2002; Landsperger et al., 2012; Milward \& Provan, 2006; Rusanen, 2013). In fact, some system-building networks use a decrease in members as a goal-alignment strategy to reach goal consensus, by some firms leaving the network or by starting a new network with only those members who share a specific objective that differs from the original network's objective. This may result from the situation that system-building 
networks emerge before the technology or the business field they are trying to develop exists. During the development of the technology and business field, the goals of the network are adjusted to the new developments. As a result, some companies may leave the network because they realize that their company goals are no longer aligned with the network goals. In conventional innovation networks, both the goal and the actor constellation are clearer from the beginning, and a reduction of network members would mainly lead to a loss of knowledge and skills. By contrast, for system-building networks a reduction in members may mean that the remaining members can more easily find goal consensus, thus making the networks more effective. In addition, we found that the networks working towards standardization preferred to start in a small constellation of actors, including 'neutral' research institutes, to enable the generation of a standard; for its implementation they increased the size of the network substantially, and they were especially interested in firm actors. This shows the importance of adjusting the size and actor types of the network to its most recent objective at a given moment in time.

Second, in contrast to what is stated in the literature, there is generally not one network manager who directs the network, but often two or sometimes more individuals who carry out this function. In the literature, the network manager is usually described as one person (Heidenreich et al., 2016; Landsperger et al., 2012). However, we found not one case in which there was only one person carrying out all the network manager's tasks as described in the literature. This is probably due to the highly technological nature of the emerging smart grid sector and the high uncertainty in which decisions are made. Technological content decisions require a different expertise and skill-set than traditional project management. Having both a project manager who is capable of effectively directing the project as well as a chairman who is an expert on the technological content and who can effectively lead discussions contributes to a better use of resources and leads to higher network effectiveness. Moreover, depending on the system-building goal, the neutrality of the leader is important, which means that an external person (non-network member) should be appointed to this position.

Third, regarding governance modes, our findings also deviated from the literature. Instead of being directed by an elected board or a network manager (Agranoff, 2006; Järvensivu \& Möller, 2009; Rampersad et al., 2010; Spieth et al., 2011; Turrini et al., 2010), Networks A-E had a board of directors, who were not elected but appointed or hand-selected. Moreover, they had two individuals acting as network manager. Furthermore, some networks had a supervisory board, or a steering group which consisted of the CEOs of the member firms. It seems that for networks with complex tasks, such as system building, slightly different governance modes are required than described in the literature.

Fourth, with regard to decision-making processes, decisions were made jointly and equitably by way of discussion, which is in line with the network management literature (Agranoff \& McGuire, 2001; McGuire \& Agranoff, 2011; Spieth et al., 2011). Although there are often voting systems, these are mainly used as a last resort. What we found for system-building networks - and what has not been emphasized in the network management literature - is that decision-making processes take place in the smallest possible constellation, i.e. by the board of directors rather than by all network members together. Network objectives may be broad, company objectives may differ, and it is a fast-changing sector; therefore it seems to be more effective to take decisions with a smaller group of people. The clear governance mechanisms in place in system-building networks provide a hierarchy which facilitates decision making at the highest level. Furthermore, prior to a decision, all necessary and relevant information will be provided to the decision makers, probably because in an emerging industry such as the smart grid sector, little information is available yet, and most situations are new. Therefore, unlike in established sectors, board members cannot base their decisions on previous experience in similar cases.
Fifth, although only few network management scholars mention the importance of project management (Cristofoli, Markovic, \& Meneguzzo, 2012; Turrini et al., 2010), it is seen as an essential key factor of collective system-building networks. The quality of project management can make or break a system-building network. Moreover, in network management literature, measurement and evaluation of performance are important for network effectiveness (Raab et al., 2013; Ritter et al., 2004; Rusanen, 2013; Spieth et al., 2011; Turrini et al., 2010). However, while considered important, it is very difficult to implement in system-building networks. In the emerging smart grid sector, it is difficult to set the right performance indicators, due to a lack of experience with the new technology, the fast-changing environment, and the high uncertainty as to how the sector will develop.

Sixth, another contrast with the network management literature is found in the way the free-rider problem is addressed. Free-riders are often mentioned as problematic in the literature (Huggins, 2000; Wijen \& Ansari, 2007) as they decrease network effectiveness. However, the free-rider problem was not experienced in the system-building networks studied. It was prevented by social pressure, i.e. explicitly discussing member contributions during meetings, or solved in personal talks, which led to the non-contributor voluntarily stepping down. In another case, the introduction of a substantial membership fee triggered non-contributors or less motivated firms to leave the network.

Seventh, in the network literature the level of trust is achieved either through previous collaborations or the outcome of-trust building processes (Järvensivu \& Möller, 2009; Milward \& Provan, 2006; Möller \& Halinen, 1999; Möller \& Svahn, 2009; Ojasalo, 2008; Ozman, 2009; Raab et al., 2013; Rampersad et al., 2010; Ritter \& Gemünden, 2003b; Ritter et al., 2004). We found that a high level of trust can also be achieved by handpicking the individuals who are part of the network's core management team, rather than only selecting member companies. This also positively influences harmony and commitment.

Our findings have several theoretical implications. With our focus on system-building networks for sustainability transitions, we contribute to the literature on network management in general, and particularly to the literature on network management in emerging business fields. We respond to the need for more empirical research on emerging business nets (Aarikka-Stenroos et al., 2014; Möller \& Svahn, 2009) by providing empirical insights into the effective management of these system-building networks. Moreover, we focused on network-level outcomes by studying network effectiveness. This has so far received limited attention in the network management literature (Rampersad et al., 2010), since most studies focus on firm-level outcomes. However, the network focus is important, given the fact that these systembuilding networks and emergent business nets generally aim to achieve collective goals. The special setting we studied also allowed us to add the empirical context of sustainability transitions to the emerging business networks literature. System-building networks operate in a fast-changing environment, under high uncertainty, and aim at implementing complex technological innovations. Being actors in sustainability transitions, they face additional challenges which have implications for the management of such networks (AarikkaStenroos \& Lehtimäki, 2014; Aarikka-Stenroos et al., 2014; Sandberg \& Aarikka-Stenroos, 2014). The conditions highlighted make the insights gained from sustainability transitions very interesting for the commercialization of radical technologies in general (Knight et al., 2015).

In this paper, we show that these specific types of networks in this specific setting need to be managed differently with regard to some of the key factors of network management in order to increase the effectiveness of the network. Compared to the existing literature, the management of our collective system-building networks differed with regard to network composition, network management structure, governance modes, decision-making processes, project management, the free-rider problem and trust-building mechanisms. All in all, we obtained a better understanding of how system-building networks can 
be managed effectively to be more successful in establishing new business fields.

\subsection{Managerial implications}

Our findings also have implications for managers in emerging business fields who want to direct and coordinate network processes. We introduced a framework that displays the key factors of network management that managers can use. Our findings related to the framework have three major implications for managers. First, the role of the network manager should be executed by two individuals: a skilled project manager, as good project management is essential for systembuilding networks, and an expert on the specific technology. Second, relational factors play a major role in network management. A high level of trust, effective network leadership, and clear boundaries are necessary to create a positive atmosphere in the network. In turn, this positive atmosphere increases the performance of the network. High trust levels may be achieved by carefully selecting network members: not only the companies but also the individuals who will be part of the team. Knowledge flows within the network are enhanced by clear decision-making mechanisms and clear boundaries for information sharing. Moreover, a participatory leadership style increases members' motivation and commitment. Third, counterintuitively, the introduction of a substantial membership fee can increase members' motivation, and a decrease in network size can have a positive impact on network effectiveness.

\subsection{Limitations and suggestions for future research}

A limitation to our study is that the results are based on networks in one sector only, the Dutch smart grid sector. However, this paper has been a first, exploratory step; moreover, we covered all national networks in this sector. We did not interview all members within each network, which could be seen as a further limitation. In the selection of the interview partners, we made sure to select network members in leading roles and with different perspectives (e.g. the project manager or a network member). Their answers did not differ very much, and the number of interview partners was sufficient to saturate our data per network.

To generalize our findings to other industries, we suggest further research on system-building networks in different emerging sectors. Other emerging fields are also likely to operate under high uncertainty. Yet, if the technologies developed are less intertwined than smart grid technology, this might have a different influence on the implementation of key factors of network management. We expect the differences found regarding the implementation of the key factors network composition, governance modes, decision-making processes, project management, the free-rider problem and trust-building mechanisms, to be also applicable to other collective system-building networks, due to the complexity of system-building tasks and the high uncertainty in which actors operate in an emerging business field. For the key factor network management leadership, our finding that two network managers are necessary may not hold if the novel technology is less complex, in which case one single leader may be sufficient, as the existing network management literature suggests. However, these assumptions need to be tested in further research.

Another limitation is that we investigated the system-building networks at a specific moment. Our data represents a snapshot in time. This has resulted in a first overview of the importance and implementation of key factors of network management. Future research could assess the dynamics between key factors of network management in different stages of network development. Furthermore, future research could focus on the design stage of collaborative system-building networks, to gain a greater understanding of the formation of these networks. Moreover, for future research it would be interesting to investigate which management activities are most important in different phases of industry emergence. The networks we studied are now at the stage which Möller and Svahn (2009) call mid-emergence, or in a late moment of the early emergence stage. We see ample opportunities for other studies to investigate emerging fields in other stages of industry emergence.

\section{Appendix 1. Empirical evidence on key factors of network management per network}

Table A.1

Overview of key factors for network management per network.



Key factors of network management

Network composition

Size - number of members 12

(at time of interview)

\section{Actor diversity \\ Governance structure}

Governance mode
Diverse

BOD, 5 projects report back to BOD
7

Diverse

BOD, all members have seat
6

Diverse

BOD; general assembly
10

All horizontal

BOD; CEO

meetings; workgroups
$12[350$

"Passive members"] Diverse

BOD; supervisory board; 4 program lines
105

Diverse

Network manager/ steering group; decentral 
Primary decision-making mechanism

Financing mechanism:

- In-kind contribution

- Monetary contribution

Network leadership structure

Official network manager Yes

External network manager No

Neutral leader

Number of leaders with different roles

Managerial processes

Strategy and goals

Shared vision

Shared vision jointly

created/prescribed

Common goal
Common goal jointly
defined or prescribed
Incentivizing members

Project management

Organization of meetings

Response to free-riders

Measuring and evaluation

\section{Task distribution \\ Transparent}

communication -

(electronic) tools of

network coordination

Relational factors

Previous collaboration experience

Trust

Harmony and commitment

Strong/supportive leadership style

Yes
Discussion until consensus

In-kind

Membership fee

\section{No}

Relatively

neutral

2 Leaders

Yes

Jointly created

Yes

Discussion until

consensus

In-kind

Financial

contributions

expected

Yes

Yes

Neutral

3 Leaders

Jointly created

Yes

Yes

Yes

Yes

No

Neutral

Relatively

neutral

2 Leaders

2 Leaders

2 Leaders

One leader/de-central

Vision imposed top-
Yes

Jointly

Motivated

members

(membership

fee)

Very important
Yes

Jointly

High intrinsic motivation

Very important

Ver

important; PM

could be

improved

Well-chaired and Well-chaired and Well-chaired

efficient

Private

efficient

Not experienced and efficient

conversation;

social pressure

prevents

yet; social

pressure

prevents

Yes, simple goal Not yet

measuring

Participatory

Participatory

Yes

Not

Well-chaired

and efficient

Private

experienced yet conversation

Not yet

Not yet

Participatory

Yes

Participatory

Yes

Yes

Jointly

High intrinsic

motivation

Very important Very important

Well-chaired and efficient

Private

conversation

Not yet

Participatory

Yes

evaluations

Tender in writing

Yes

No network-level meetings

Private conversation

(during projects) Yes

Prescribed

Have to reach receiving (full) subsidy money

ing pilots: very

important

Yes, milestone
evaluations
Tender in writing
Yes
down by Ministry of

$\begin{array}{llllll}\text { Medium } & \text { High } & \text { Medium } & \text { High } & \text { High } & \text { Low } \\ \text { High } & \text { Very high } & \text { High } & \text { High } & \text { Very high } & \text { Medium } \\ \text { High } & \text { Very high } & \text { High } & \text { High } & \text { Very high } & \text { Medium } \\ +/- & ++ & + & + & ++ & -\end{array}$

\section{References}

Aarikka-Stenroos, L., \& Lehtimäki, T. (2014). Commercializing a radical innovation: Probing the way to the market. Industrial Marketing Management, 43(8), 1372-1384. http://dx.doi.org/10.1016/j.indmarman.2014.08.004.

Aarikka-Stenroos, L., Sandberg, B., \& Lehtimäki, T. (2014). Networks for the commercialization of innovations: A review of how divergent network actors contribute. Industrial Marketing Management, 43(3), 365-381. http://dx.doi.org/10.1016/j. indmarman.2013.12.005.

Agranoff, R. (2006). Inside collaborative networks: Ten lessons for public managers. Public Administration Review, 66(s.1), 56-65. http://dx.doi.org/10.1111/j.1540-6210. 2006.00666.x.

Agranoff, R., \& McGuire, M. (2001). Big questions in public network management research. Journal of Public Administration Research and Theory, 11(3), 295-326. http://dx.doi.org/10.1093/oxfordjournals.jpart.a003504.

Chesbrough, H. W., \& Appleyard, M. M. (2007). Open innovation and strategy. California Management Review, 50(1), 57-76.

Choi, T. Y., \& Hong, Y. (2002). Unveiling the structure of supply networks: Case studies in Honda, Acura, and DaimlerChrysler. Journal of Operations Management, 20(5), 469-493. http://dx.doi.org/10.1016/S0272-6963(02)00025-6.

Cristofoli, D., Markovic, J., \& Meneguzzo, M. (2012). Governance, management and performance in public networks: How to be successful in shared-governance networks. Journal of Management and Governance, 18(1), 77-93. http://dx.doi.org/10. 1007/s10997-012-9237-2.

Dhanaraj, C., \& Parkhe, A. (2006). Orchestrating innovation networks. Academy of Management Review, 31(3), 659-669.

Dooley, L., \& O'Sullivan, D. (2007). Managing within distributed innovation networks. 
International Journal of Innovation Management, 11(3), 397-416.

Ford, D., \& Håkansson, H. (2013). Competition in business networks. Industrial Marketing Management, 42(7), 1017-1024. http://dx.doi.org/10.1016/j.indmarman.2013.07. 015.

Freytag, P. V., \& Ritter, T. (2005). Dynamics of relationships and networks - Creation, maintenance and destruction as managerial challenges. Industrial Marketing Management, 34(7), 644-647. http://dx.doi.org/10.1016/j.indmarman.2005.06.002.

Geels, F. W. (2002). Technological transitions as evolutionary reconfiguration processes: A multi-level perspective and a case-study. Research Policy, 31(8), 1257-1274. http:// dx.doi.org/10.1016/S0048-7333(02)00062-8.

Geels, F. W. (2005). Processes and patterns in transitions and system innovations: Refining the co-evolutionary multi-level perspective. Technological Forecasting and Social Change, 72(6), 681-696. http://dx.doi.org/10.1016/j.techfore.2004.08.014.

Geels, F. W. (2010). Ontologies, socio-technical transitions (to sustainability), and the multi-level perspective. Research Policy, 39(4), 495-510. http://dx.doi.org/10.1016/ j.respol.2010.01.022.

Gulati, R. (1998). Alliances and networks. Strategic Management Journal, 19(4), 293-317.

Gulati, R., Nohria, N., \& Zaheer, A. (2000). Strategic networks. Strategic Management Journal, 21(3), 203-215.

Hagedoorn, J., \& Schakenraad, J. (1994). The effect of strategic technology alliances on company performance. Strategic Management Journal, 15(4), 291-309.

Håkansson, H., \& Ford, D. (2002). How should companies interact in business networks? Journal of Business Research, 55, 133-139. http://dx.doi.org/10.1016/S01482963(00)00148-X.

Håkansson, H., \& Persson, G. (2004). Supply chain management: The logic of supply chains and networks. International Journal of Logistics Management, 15(1), 11-26.

Heidenreich, S., Landsperger, J., \& Spieth, P. (2016). Are innovation networks in need of a conductor? Examining the contribution of network managers in low and high complexity settings. Long Range Planning, 49(1), 55-71. http://dx.doi.org/10.1016/j. lrp.2014.03.003.

Huggins, R. (2000). The success and failure of policy-implanted inter-firm network initiatives: Motivations, processes and structure. Entrepreneurship and Regional Development, 12(2), 111-135. http://dx.doi.org/10.1080/089856200283036.

Järvensivu, T., \& Möller, K. (2009). Metatheory of network management: A contingency perspective. Industrial Marketing Management, 38(6), 654-661. http://dx.doi.org/10. 1016/j.indmarman.2009.04.005.

Kemp, R., Schot, J., \& Hoogma, R. (1998). Regime shifts to sustainability through processes of niche formation: The approach of strategic niche management. Technology Analysis \& Strategic Management, 10(2), 175-198. http://dx.doi.org/10.1080/ 09537329808524310.

Klijn, E.-H., Steijn, B., \& Eldenbos, J. (2010). The impact of network management on outcomes in governance networks. Public Administration, 88(4), 1063-1082. Retrieved from http://www.nomos-shop.de/Bozzini-Enjolras-GoverningAmbiguities/productview.aspx? product $=13716 \&$ rtoc $=124$.

Knight, L., Pfeiffer, A., \& Scott, J. (2015). Supply market uncertainty: Exploring consequences and responses within sustainability transitions. Journal of Purchasing and Supply Management, 21(3), 167-177. http://dx.doi.org/10.1016/j.pursup.2015.04. 002 .

Landsperger, J., Spieth, P., \& Heidenreich, S. (2012). How network managers contribute to innovation network performance. International Journal of Innovation Management, 16(6), http://dx.doi.org/10.1142/S1363919612400099.

McGuire, M. (2002). Managing networks: Propositions on what managers do and why they do it. Public Administration Review, 62(5), 599-609.

McGuire, M., \& Agranoff, R. (2011). The limitations of public management networks. Public Administration, 89(2), 265-284. http://dx.doi.org/10.1111/j.1467-9299.2011. 01917.x.

Milward, H. B., \& Provan, K. G. (2003a). Managing networks effectively. Washington, DC: National Public Management Research Conference, Georgetown University. Retrieved from http://www.pmranet.org/conferences/georgetownpapers/Milward. pdf.

Milward, H. B., \& Provan, K. G. (2003b). Managing the hollow state collaboration and contracting. Public Management Review, 5(1), 1-18. http://dx.doi.org/10.1080/ 1461667022000028834

Milward, H. B., \& Provan, K. G. (2006). A manager's guide to choosing and using collaborative networks. DC: Washington.

Milward, H. B., Provan, K. G., Fish, A., Isett, K. R., \& Huang, K. (2009). Governance and collaboration: An evolutionary study of two mental health networks. Journal of Public Administration Research and Theory, 20(Suppl. 1), i125-i141. http://dx.doi.org/10. 1093/jopart/mup038.

Möller, K. (2010). Sense-making and agenda construction in emerging business networks - How to direct radical innovation. Industrial Marketing Management, 39(3), 361-371. http://dx.doi.org/10.1016/j.indmarman.2009.03.014.

Möller, K., \& Halinen, A. (1999). Business relationships and networks: Managerial challenge of network era. Industrial Marketing Management, 28(5), 413-427. http://dx.doi. org/10.1016/S0019-8501(99)00086-3.

Möller, K., \& Rajala, A. (2007). Rise of strategic nets - New modes of value creation. Industrial Marketing Management, 36(7), 895-908. http://dx.doi.org/10.1016/j. indmarman.2007.05.016.

Möller, K., \& Svahn, S. (2003). Managing strategic nets a capability perspective. Marketing Theory, 3(2), 209-234. http://dx.doi.org/10.1177/14705931030032002.

Möller, K., \& Svahn, S. (2006). Role of knowledge in value creation in business nets. Journal of Management Studies, 43(5), 985-1007.

Möller, K., \& Svahn, S. (2009). How to influence the birth of new business fields - Network perspective. Industrial Marketing Management, 38, 450-458. http://dx.doi.org/10. 1016/j.indmarman.2008.02.009.

Musiolik, J., \& Markard, J. (2010). Innovation networks and resources in technological innovation systems: Insights from the field of stationary fuell cells in Germany. (Winter 2010 PhD Conference. Aalborg).

Musiolik, J., Markard, J., \& Hekkert, M. P. (2012). Networks and network resources in technological innovation systems: Towards a conceptual framework for system building. Technological Forecasting and Social Change, 79(6), 1032-1048. http://dx. doi.org/10.1016/j.techfore.2012.01.003.

Nalebuff, B., \& Brandenburger, A. M. (1996). Coopetition. Philadelphia, PA: Harper Collins Business.

Ojasalo, J. (2008). Management of innovation networks: A case study of different approaches. European Journal of Innovation Management, 11(1), 51-86. http://dx.doi org/10.1108/14601060810845222.

O'Toole, L. J. J. (1997). Treating networks seriously: Practical and researched-based agendas in public administration. Public Administration Review, 75(1), 45-52.

Ozman, M. (2009). Inter-firm networks and innovation: A survey of literature. Economics of Innovation and New Technology, 18(1), 39-67. http://dx.doi.org/10.1080/ 10438590701660095.

Page, S. (2003). Entrepreneurial strategies for managing interagency collaboration. Journal of Public Administration Research and Theory, 13(3), 311-339. http://dx.doi. org/10.1093/jopart/mug026.

Paquin, R. L., \& Howard-Grenville, J. (2013). Blind dates and arranged marriages: Longitudinal processes of network orchestration. Organization Studies, 34. http://dx. doi.org/10.1177/0170840612470230.

Partanen, J., \& Möller, K. (2012). How to build a strategic network: A practitioner-oriented process model for the ICT sector. Industrial Marketing Management, 41(3), 481-494. http://dx.doi.org/10.1016/j.indmarman.2011.05.002.

Planko, J., Cramer, J. M., Chappin, M. M. H., \& Hekkert, M. P. (2016). Strategic collective system building to commercialize sustainability innovations. Journal of Cleaner Production, 112, 2328-2341. http://dx.doi.org/10.1016/j.jclepro.2015.09.108.

Provan, K. G., Fish, A., \& Sydow, J. (2007). Interorganizational networks at the network level: A review of the empirical literature on whole networks. Journal of Management, 33(3), 479-516. http://dx.doi.org/10.1177/0149206307302554.

Provan, K. G., \& Kenis, P. (2008). Modes of network governance: Structure, management, and effectiveness. Journal of Public Administration Research and Theory, 18(2), 229-252. http://dx.doi.org/10.1093/jopart/mum015.

Raab, J., Mannak, R. S., \& Cambré, B. (2013). Combining structure, governance, and context: A configurational approach to network effectiveness. Journal of Public Administration Research and Theory, 25(2), 479-511. http://dx.doi.org/10.1093/ jopart/mut039.

Rampersad, G., Quester, P., \& Troshani, I. (2010). Managing innovation networks: Exploratory evidence from ICT, biotechnology and nanotechnology networks. Industrial Marketing Management, 39(5), 793-805. http://dx.doi.org/10.1016/j indmarman.2009.07.002.

Ritter, T., \& Gemünden, H. G. (2003a). Interorganizational relationships and networks: An overview. Journal of Business Research, 56(9), 691-697. http://dx.doi.org/10. 1016/S0148-2963(01)00254-5.

Ritter, T., \& Gemünden, H. G. (2003b). Network competence: Its impact on innovation success and its antecedents. Journal of Business Research, 56(9), 745-755. http://dx. doi.org/10.1016/S0148-2963(01)00259-4.

Ritter, T., \& Gemünden, H. G. (2004). The impact of a company's business strategy on its technological competence, network competence and innovation success. Journal of Business Research, 57(5), 548-556. http://dx.doi.org/10.1016/S0148-2963(02) 00320-X.

Ritter, T., Wilkinson, I. F., \& Johnston, W. J. (2004). Managing in complex business networks. Industrial Marketing Management, 33(3), 175-183. http://dx.doi.org/10. 1016/j.indmarman.2003.10.016.

Rusanen, H. (2013). Managing constant change in innovation networks. Proceedings of the 22nd Nordic Academy of management conference. Rykjavik.

Russell, J. L., Meredith, J., Childs, J., Stein, M. K., \& Prine, D. W. (2015). Designing interorganizational networks to implement education reform: An analysis of state race to the top applications. Educational Evaluation and Policy Analysis, 37(1), 92-112. http:// dx.doi.org/10.3102/0162373714527341.

Sandberg, B., \& Aarikka-Stenroos, L. (2014). What makes it so difficult? A systematic review on barriers to radical innovation. Industrial Marketing Management, 43(8), 1293-1305. http://dx.doi.org/10.1016/j.indmarman.2014.08.003.

Spieth, P., Clauss, T., \& Landsperger, J. (2011). Managing innovation networks in the engineering industry: Moderating effects of spatial proximity. Copenhagen: DRUID.

Thorgren, S., Wincent, J., \& Örtqvist, D. (2009). Designing interorganizational networks for innovation: An empirical examination of network configuration, formation and governance. Journal of Engineering and Technology Management, 26(3), 148-166. http://dx.doi.org/10.1016/j.jengtecman.2009.06.006.

Tricoire, A. (2015). Uncertainty, vision, and the vitality of the emerging smart grid. Energy Research \& Social Science, 9, 21-34. http://dx.doi.org/10.1016/j.erss.2015.08. 028.

Turrini, A., Cristofoli, D., Frosini, F., \& Nasi, G. (2010). Networking literature about determinants of network effectiveness. Public Administration, 88(2), 528-550. http:// dx.doi.org/10.1111/j.1467-9299.2009.01791.x.

van der Valk, T., Chappin, M. M. H., \& Gijsbers, G. W. (2011). Evaluating innovation networks in emerging technologies. Technological Forecasting and Social Change, 78(1), 25-39. http://dx.doi.org/10.1016/j.techfore.2010.07.001.

Van Der Schoor, T., \& Scholtens, B. (2015). Power to the people: Local community initiatives and the transition to sustainable energy. Renewable and Sustainable Energy Reviews, 43, 666-675. http://dx.doi.org/10.1016/j.rser.2014.10.089.

Verbong, G. P. J., Beemsterboer, S., \& Sengers, F. (2013). Smart grids or smart users? Involving users in developing a low carbon electricity economy. Energy Policy, 52, 117-125. http://dx.doi.org/10.1016/j.enpol.2012.05.003.

Weiss, E. S., Anderson, R. M., \& Lasker, R. D. (2002). Making the most of collaboration: 
Exploring the relationship between partnership synergy and partnership functioning. Health Education \& Behavior, 29(6), 683-698.

Wijen, F., \& Ansari, S. (2007). Overcoming inaction through collective institutional entrepreneurship: Insights from regime theory. Organization Studies, 28(7), 1079-1100. http://dx.doi.org/10.1177/0170840607078115.

Wilhelm, M. M. (2011). Managing coopetition through horizontal supply chain relations: Linking dyadic and network levels of analysis. Journal of Operations Management, 29(7-8), 663-676. http://dx.doi.org/10.1016/j.jom.2011.03.003.

Yin, R. K. (2009). Case study research. Design and methods (4th ed.). Thousand Oaks: Sage Publications.

Julia Planko is a PhD candidate at Utrecht University. She holds a degree in International Economics and in Business Management and teaches Corporate Social Responsibility, Marketing and Economics at the HU University of Applied Sciences Utrecht. Her research focuses on eco-innovations and strategic management in innovation ecosystems.
Maryse M.H. Chappin is Assistant Professor of Innovation Studies at Utrecht University. Her research focuses on eco-innovation and the success of collaborations and networks. She also studies the role of the institutional environment on the innovation process.

Jacqueline M. Cramer is Professor of Sustainable Innovation at Utrecht University, strategic advisor of the Utrecht Sustainability Institute and director of her own consultancy firm on sustainable entrepreneurship. Before she was the Dutch Minister of Housing, Spatial Planning and the Environment (2007-2010).

Marko P. Hekkert is Full Professor of Innovation System Dynamics and chairman of the Copernicus Institute of Sustainable Development at Utrecht University; much of his research time is devoted to studying the process of sustainable technological change and eco-innovation. 